\title{
Emergence delirium: a narrative review
}

\author{
Omar Viswanath ${ }^{1 *}$, Bryan Kerner ${ }^{1+}$, Yuel-Kai Jean ${ }^{2 \dagger}$, Roy Soto ${ }^{3+}$ and Gerald Rosen ${ }^{1+}$
}

*Correspondence: viswanoy@gmail.com

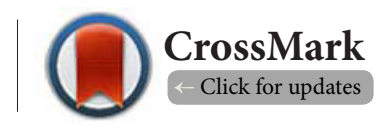

'These authors contributed equally to this work.

'Department of Anesthesiology, Mount Sinai Medical Center, Miami Beach, Florida, USA.

${ }^{2}$ Nova Southeastern University, College of Osteopathic Medicine, Fort Lauderdale, Florida, USA.

${ }^{3}$ Department of Anesthesiology, Beaumont Health System, Royal Oak, Michigan, USA.

\begin{abstract}
Emergence delirium (ED) is a post-surgical phenomenon associated with an increase in morbidity, mortality and resource utilization. A systematic review of all current treatment modalities for this condition is imperative given its prevalence during postoperative recovery. This review scrutinizes a number of studies in order to better characterize ED, with particular focus paid to the condition's etiology, associated risk factors, prevention and management. Extensive studies have been conducted on the pediatric population with little attention directed towards the adult and geriatric age groups. Despite this, evidence-based protocols for the management of this condition are still lacking for all age groups. In order to ensure cost effective management and improved safety outcomes for ED, future research should establish and further improve upon screening protocols to identify at risk patients, in addition to formulating a standardized treatment regimen for perioperative patients at risk.
\end{abstract}

Keywords: Emergence delirium, anesthesia recovery period, anesthetic issues and peri-operative care, perioperative complications, preoperative evaluation and anesthesia risk, complications in the post anesthesia care unit

\section{Introduction}

Emergence delirium (ED) is a post-surgical phenomenon first identified in the 1960's when Eckenhoff et al., studied over 14,000 patients who experienced unusual post-operative behavioral disturbances which they termed "excitement". This occurred in $5.3 \%$ of the sample patients [1]. These symptoms were found to be associated with an increase in morbidity, mortality and resource utilization [2-5]. Since this landmark study, research on this condition has focused largely on the etiology, risk factors and management. Despite these efforts, consensus regarding an evidence-based treatment protocol has yet to be established. This review will analyze current literature, as well as highlight areas for further research, with the intention of providing insight as to how ED management protocols can be standardized. The high prevalence, substantial financial burden, and significant dangers imposed on both the patients and the health care providers underscore the importance for a systematic review of ED.

\section{Review}

\section{Presentation}

ED has been described as a mental disturbance during the recovery from general anesthesia into the post anesthesia recovery unit. It may consist of hallucinations, delusions, and confusion that manifests as restlessness, moaning, involuntary physical activity, and thrashing [6]. This condition has been shown to occur in $5 \%$ to $10 \%$ of general surgery patients of all ages. Incidence of ED increases significantly for those undergoing hip surgery, having been reported to occur in $16 \%$ to $62 \%$ of patients [7]. Additionally, a higher rate of delirium has been seen in patients over age 80 who suffer from functional impairment to their activities of daily living, with underlying medical comorbidities, and patients medicated preoperatively with benzodiazepines, beta blockers, or opiods [8-10]. Moreover, ED primarily occurs within the first 30 minutes of recovery time and typically resolves within an hour of onset compared to postoperative delirium (POD) which can last for days. This self-limiting condition should be differentiated from postoperative cognitive dysfunction (POCD), a prolonged postoperative state of altered mentation and cognitive deterioration with an increased risk of morbidity [11].

\section{Mechanism \\ Neurophysiology}

ED was initially categorized as a pseudopsychological disorder.

(c) 2015 Viswanath et al; licensee Herbert Publications Ltd. This is an Open Access article distributed under the terms of Creative Commons Attribution License (http://creativecommons.org/licenses/by/3.0). This permits unrestricted use, distribution, and reproduction in any medium, provided the original work is properly cited. 
Viswanath et al. Journal of Anesthesiology \& Clinical Science 2015,

The onset of ED can be provoked by stress, a characteristic shared by many psychiatric conditions, most notably posttraumatic stress disorder (PTSD). Similarities between ED and PTSD are further evidenced by examining the pathophysiology of both PTSD and hearing recovery during the post-anesthesia period. Interestingly, the first sense to return during emergence from anesthesia is hearing, a sense that is made possible by the synapse between the acoustic thalamus and the lateral nucleus of the amygdala (LA) [12]. During post-anesthesia recovery, this connection is also responsible for auditory fear conditioning by exaggerating an inappropriate response to auditory stimuli [13]. Given the similarities between ED and PTSD, insight into the mechanism of inappropriately enhanced response to auditory stimuli during the postoperative period may be explained by examining studies that have outlined the pathophysiology behind PTSD. Specifically, studies have shown that a heightened response in PTSD patients subsequently causes a down regulation of large-conductance $\mathrm{Ca}^{2+}$ activated potassium channels (BKCa) in the LA $[14,15]$. The decrease in $\mathrm{BKCa}$ channels is associated with an increase in excitatory activity evoked by NMDA postsynaptic potentials at the thalamo-LA synapse, therefore enhancing stress induced behavior [16]. Under normal function, activation of BKCa channels is responsible for decreasing stress-induced behavior.

An uncomplicated postoperative emergence mimics Guedel Stage II (excitement stage) of anesthesia. Moreover, studies have shown a pronounced slowing pattern on the electroencephalogram in patients that are experiencing delirium [17]. This finding may be attributable to the interference of neurotransmitter metabolism and function within the central nervous system. An example of this phenomenon has been documented in cases of substance induced hyper and hypostimulation of gamma aminobutyric acid (GABA) receptors [18].

Additional studies have also implicated disturbances to central cholinergic pathways as a cause of delirium. Acetylcholine $(\mathrm{ACh})$, which regulates awareness and arousal, is found in lower concentrations in geriatric patients. The diminished quantities of ACh heighten sensitivity and predispose the older population, especially those medicated with anticholinergic agents, to delirium. Disturbance of other important neurotransmitters that regulate sleep and arousal, specifically serotonin and noradrenaline, have also been associated with delirium [18]. Many studies have attributed the disruption of circadian rhythm as a cause of delirium in the operative setting [19-21]. In general, the distinction of whether ED results from substance induced delirium, PTSD, or other neurological factors has not yet been understood and requires further investigation.

To date, there have been a limited amount of studies investigating the neurophysiology basis behind ED. A study by Yasui et al., investigated that inhalation anesthetics have been known to exert transient paradoxical "excitatory" effects in the animals and human patients, more predominantly in children [22]. This excitation is of serious clinical concern, particularly when occurring during the emergence of inhalation anesthesia.
The study recorded the membrane current and potential of the locus coeruleus (LC) neurons in brainstem slices and analyzed the effects of inhalation and nonvolatile anesthetics thereon, targeting the LC in the pons. The results of their study found that there was in fact a specific excitation of the LC neurons by inhalation anesthetics, especially sevoflurane, which ultimately plays an important role in this paradoxical excitation [22].

Another study, by Lim at al., attempted to explain the neurophysiology behind hyperexcitatory behaviors occurring after sevoflurane anesthesia [23]. They postulated that the excitation may result from the potentiation by sevoflurane of GABAergic depolarization/excitation in neocortical neurons, cells implicated in the genesis of arousal and consciousness. Their study sought to provide evidence for this hypothesis with rats, the neocortical neurons of which are known to respond to GABA ( $\gamma$-aminobutyric acid) with depolarization/ excitation at early stages of development. Their study employed behavioral tests and electrophysiological recordings in neocortical slice preparations, the results of which found that sevoflurane produced post-anesthetic hyperexcitatory behaviors (PAHBs) in postnatal day 1-15 rats. On the basis of their results, they concluded that sevoflurane may produce PAHBs by potentiating GABAergic depolarization/excitation in neocortical neurons [23].

\section{Organic causes}

While significant evidence supports disruption to the central nervous system as having a prominent role in the development of ED, other studies suggest that ED may have an endocrine etiology. Studies have identified cases of elevated serum cortisol levels postoperatively. This cortisol surge has been correlated with an increased incidence of post-operative confusion $[\mathbf{2 4 , 2 5 ]}$.

ED may be attributed to pathological processes affecting the cardiopulmonary system. Intraoperative reduction in carbon dioxide $\left(\mathrm{CO}_{2}\right)$ levels can decrease cerebral blood flow via vasoconstriction. Extended periods of hypocapnia causes damage to the caudoputamen and may be responsible for some of the characteristic symptoms of postoperative delirium [26]. Another metabolic derangement that may contribute to ED is hypercarbia. Perioperative hypoventilation results in elevated $\mathrm{CO}_{2}$ levels, promoting an acidotic state that alters consciousness. Importantly, altered blood $\mathrm{O}_{2}$ levels may also contribute to the symptoms associated with ED. Predisposition to delirium is seen in hypoxemic states evidenced by myocardial ischemia, cerebral ischemia, and altered drug therapy sensitivities.

\section{Etiological risk factors}

Several theories have discussed the etiological factors associated with ED. These risk factors can be subdivided into preoperative factors and postoperative risk factors. It is important to note that overlap commonly exists between categories. 


\section{Preoperative risk factors Genetics}

Agnoletti et al., hypothesized that certain genetic polymorphisms (regions of the IL-1, IL-6, IL-10, TNF-alpha genes) play an important role in the immune response and inflammatory pathways that may in fact predispose a patient to POD [27]. A case control study by Yani consisting of 351 patients aged 65 years and over found IL- 6 concentration to be higher in POD patients [28]. Yani concluded that elevated premorbid IL-6 levels could be predictive for the development of delirium. Similar results were shown by Liu et al., who discovered higher serum IL-6 levels postoperatively were associated with a significantly increased risk of developing delirium in patients 60 years and older (hazard ratio 1.514) [29].

Along with inflammatory markers, Apolipoprotein E e4 has also been looked at as a risk factor for POD. In 2007, Leung et al., determined that patients with one copy of the e4 allele were more likely to have an increased risk of early POD (odds ratio, $3.64 ; 95 \%$ confidence interval, 1.51-8.77) compared with those without the e4 allele. Their findings support the theory that early POD is predicated, in large part, on the interaction between genes and factors imposed by surgery and anesthesia. Conversely, apolipoprotein e4 carrier status was not associated with an increased risk of early POD [30]. At present, there are insufficient studies tothoroughly explain the basis behind genetic predisposition to ED.

\section{Age}

Age plays a considerable role in the etiology of ED. Patients under the age of 40 and also over the age of 64 have a higher incidence of ED [31]. Several authors have demonstrated that pediatric patients that are under the age of 5 years are vulnerable to altered behavior upon recovery from anesthesia [32-35]. Numerous studies have examined the role of brain maturation on delirium, with some relating ED susceptibility in children to the development of the hippocampus and cholinergic function [35,36]. Further, a study by Martini showed that neurotransmitter levels in pediatric brains were analogous to levels in brains that had undergone normal age-related changes. Diminished levels of ACh, dopamine, norepinephrine and aminobutyric acid were neurophysiological findings characteristic of both the geriatric and pediatric populations [35]. Disturbance to these neurotransmitters have been implicated as precipitating factors for delirium in a significant number of studies (refer to section 3.1.1 Neurophysiology).

\section{Benzodiazepines}

Studies have shown a strong correlation between preoperative administration of benzodiazepines and increased risk of ED. Doyle in 1994 published the first case of ED associated with midazolam use [37]. This was confirmed in Lepouse's study of 1359 patients in which it was determined that the use of benzodiazepines before surgery nearly doubled the risk of $\mathrm{ED}(\mathrm{OR}=1.838)$ [5]. Additionally, Radtke produced a study of
1,868 patients that showed premedication with benzodiazepines and higher postoperative pain scores as significant risk factors for ED [31]. It is important to note that while preoperative administration with benzodiazepines has been correlated with a significant risk for ED, there are numerous studies that have purported dramatically lower incidences of ED with perioperative benzodiazepine administration [38,39].

\section{Perioperative risk factors Inhalation anesthetics}

The recent surge in ED cases [40] is a reflection of the gaining popularity of sevoflurane and desflurane. Specifically, there are a significant number of studies linking these anesthetics to a higher incidence of ED [41-45]. It is believed that the low blood solubility characteristic of these newer inhaled anesthetics promote a rapid awakening that concurrently increases susceptibility to ED [42].

Presently, there is strong evidence supporting the variable extent to which different inhalation anesthetics affect ED incidences. Early literature found desflurane to have an increased risk for ED relative to both sevoflurane and halothane [42]. Variable predisposition to ED between the different inhalation anesthetics was also supported by Aono et al., who found that ED appeared more often with sevoflurane than with halothane in preschool boys aged $3-5$ years ( $40 \%$ vs. $10 \%)$. Interestingly, the difference was not observed in the school-aged population. The authors of that study speculate that stress related to rapid awakening in an unfamiliar environment, combined with psychological immaturity, are the principal etiological factors that precipitate ED in the pre-school age group [46].

The causative relationship between inhalation anesthetics and ED is affected by the concurrent use of other medications. Supporting the findings by Aono et al., a study by Kuratini and Oi, examining 4 randomized controlled trials ( $n=1,252$ sevoflurane and $n=1,111$ halothane) found that children anesthetized with sevoflurane exhibited a greater incidence of ED than those anesthetized with halothane [47]. However, Murray et al., found that premedication with oxycodone increased the incidence of ED in pediatric patients who were anesthetized with halothane compared tosevoflurane [43].

\section{Surgery}

Considerable evidence exists demonstrating that the frequency of ED is dependent on the type of surgical procedure. Using multivariate analysis by backward binary stepwise logistic regression, Lepousé et al., studied 1359 adults patients and determined breast surgery $(\mathrm{OR}=5.190)$ and abdominal surgery $(O R=3.206)$ were the surgeries with the highest risk of developing ED. Surgical procedures that involve the tonsils, thyroid, middle ear, and eye have also been reported to have higher incidences of postoperative agitation and restlessness $[33,41,48,49]$.

In addition to the type of surgical procedure, a number of surgical complications have also been implicated as pre- 
cipitating causes of ED. Specifically, evidence indicates that prolonged length of surgery, hemorrhagic events, postoperative complications necessitating blood transfusions, and postoperative hematocrit $<30 \%$ have all been attributed to higher instances of delirium $[5, \mathbf{1 1}]$. Currently, there is insufficient evidence supporting the precise mechanism through which different surgeries and surgical complications affect ED variability.

\section{Pain}

The patient's level of pain is also a contributing factor in the risk for ED. Concurrent to the level of pain perceived by the patient is the type of surgery as well as the surgical site, both of which will be contributing variables to elevated levels of postoperative pain, thus subsequently increasing the risk of ED.

\section{Diagnosis}

The DSM V criteria for diagnosing ED are not well described. Several assessment tools have been established to guide diagnosis, among which includes the Sedation-Agitation Scale (SAS). Described by Riker et al., this diagnostic tool quantifies patient behavior on a 7 point numerical scale from unarousable to dangerous agitation [50]. Another commonly used diagnostic tool is The Richmond Agitation Sedation Scale (RASS). This screening protocol, which has been found to have high reliability and validity in both medical and surgical patients while correlating highly with the SAS $[3,51]$, categorizes patients from unarousable (score of -5 ) to combative (score of +4$)$.

\section{Prevention and treatment \\ Pharmacological management \\ Benzodiazepines}

Despite the increased risk of ED in preoperative administration of benzodiazepines, several studies have demonstrated lower incidences of ED when benzodiazepines are administered in the perioperative stage [38,39]. In 2013, Zhang et al., performed a meta-analysis on a total 447 children which saw prophylactic administration of midazolam significantly decrease the incidence of ED in pediatric patients. These findings corroborated with a later study by Cho et al., which examined the association of perioperative intravenous midazolam administration and ED incidence in pediatric patients undergoing surgery for strabismus. The study determined that $0.03 \mathrm{mg} / \mathrm{kg}$ of midazolam administered just prior to the end of surgery reduced ED without delaying the emergence time [39].

\section{NSAIDS and opioids}

Pain has been well investigated as a risk factor for ED, mainly in the pediatric population [42,52-59]. The majority of research shows that adequate pain management decreases the incidence of ED. The efficacy of ketorolac in preventing ED was demonstrated in a study by Davis et al., In that study, ketorolac administration decreased the incidence of ED three to fourfold after myringotomy when patients were anesthetized with either halothane or sevoflurane [42]. Contradictory findings were observed in a more recent study by Kim et al., in pediatric patients that received sevoflurane. Specifically, 85 pediatric patients aged 3 to 7 years who received $1 \mathrm{mg} / \mathrm{kg}$ of ketorolac were found to have no significant reduction in the incidence and severity of ED.

While the efficacy of NSAIDS in the treatment and prevention of ED remains uncertain, an overwhelming majority of literature suggests opioids are highly effective in treating and preventing the condition. Dong et al., found that intraoperative remifentanil decreased the incidence of ED in children undergoing adenotonsillectomy [60]. Fentanyl, given either IV $2.5 \mu \mathrm{g} / \mathrm{kg}$ or intranasally $2 \mu \mathrm{g} / \mathrm{kg}$ during moderately painful surgery, has also been shown to decrease emergence agitation in children [61-64]. Bong et al., confirmed the preventative effects of fentanyl and further identified a lack of fentanyl as an independent risk factor for ED [34].

\section{Clonidine}

Two commonly used a2-adrenergic agonists, specifically clonidine and dexmedetomidine, are gaining popularity within operating rooms as effective management options for ED. A recent meta-analysis involving 669 patients analyzed the efficacy of a2-adrenergic agonists in the management of ED. The results of that study indicated significantly reduced cases of ED in patients treated with intravenous a2-adrenergic agonists (odds ratio 0.28) [65]. In 2010, Dahmani et al., constructed a meta-analysis of ten studies which compared premedication of clonidine with benzodiazepines in children aged 1-12. Clonidine, in comparison with midazolam, exhibited a superior effect on sedation at induction, decreased the incidence of emergence agitation, and produced a more effective early post-operative analgesia [66]. Interestingly, a separate study involving 767 children found a synergistic effect, demonstrating a significant reduction in the incidence of ED when administering clonidine in combination with midazolam [38].

\section{Dexmedetomidine}

The relatively benign safety profile and improved efficacy relative to other medications has made dexmedetomidine a preferred agent of choice. In 2008, Enlow and Ardizzone published a review of four randomized controlled trials and found that perioperative administration of dexmedetomidine significantly reduced the incidence of ED in children without increasing the risk of side effects $[57,58,67-69]$. Similar results were seen in a more recent study which found dosages of dexmedetomidine between 1.0 and $1.43 \mu \mathrm{g} / \mathrm{kg}$ safely attenuating ED in 25 pediatric patients after sevoflurane anesthesia [70].

Aside from the acceptable safety margin and improved efficacy in managing ED, preference for dexmedetomidine can be explained by its secondary benefits of improved symptomatic coverage. For instance, in 2013, Ali and Abdellatif found that perioperative treatment with $0.3 \mathrm{ug} / \mathrm{kg}$ dexmedeto- 
midine was more effective than $1 \mathrm{mg} / \mathrm{kg}$ propofol in decreasing the incidence and severity of ED in children undergoing adenotonsillectomy. That same study also found that dexmedetomidine significantly reduced the incidence of postoperative nausea, vomiting, chills, and restlessness with decreased postoperative pain, extubation time and emergence time compared to propofol, without affecting the length of stay in the post anesthesia care unit (PACU) [71]. Moreover, the additional advantages of dexmedetomidine over midazolam were seen in a double-blinded randomized controlled trial conducted by Yuen et al., The study found that intranasal dexmedetomidine for premedication produced more sedation than oral midazolam with comparable side effects [72].

\section{Ketamine}

Ketamine has been one of the more extensively studied pharmacological agents in the management of ED. Debate about the efficacy of ketamine in the management of ED is largely driven by earlier studies that linked ketamine to an increased risk of ED [1,73-75]. However, more recent studies have contradicted these findings [76-79]. In a study where 80 pediatric patients were given oral ketamine $6 \mathrm{mg} / \mathrm{kg}, 18 \%$ developed ED, much lower than the $56 \%$ reported in the placebo group [76]. These results coincided with a randomized clinical trial by Eghbal et al., which determined low dose ketamine during induction of anesthesia improved both emergence agitation and postoperative pain following adenotonsillectomy in children [79]. Similarly, Abu-Shahwan and Chowdary's randomized double blind study of 85 children aged 4-7 years demonstrated that treatment with ketamine $0.25 \mathrm{mg} / \mathrm{kg}$ decreased the incidence of emergence agitation [77].

A prospective data collection by Treston et al., which analyzed 745 patient records, suggested that ketamine can result in a pleasant emergence phenomenon that is neither distressing on awakening nor associated with long term sequelae. These altered pleasant perceptions were seen in $39 \%$ of patients. The same study also noted rare self-limiting cases of anxiety and distress on awakening from ketamine sedation experienced by $2.1 \%$ of patients. The authors argue that the benefits of ketamine significantly outweigh the risks and subsequently conclude that physicians should not be deterred from using ketamine as a form of procedure sedation [78].

Presently, emerging studies strongly favor treatment with ketamine, particularly in combination with dexmedetomidine. Jia et al., investigated ketamine and dexmedetomidine together in 160 children aged between 2 and 6 years. The study concluded that the administration of $2 \mu \mathrm{g} / \mathrm{kg}$ intranasal dexmedetomidine and $3 \mathrm{mg} / \mathrm{kg}$ oral ketamine had the highest efficacy while avoiding excessive side-effects or postoperative complications [80].

\section{Conclusion}

Implications

ED is a preventable and treatable condition. Refining man- agement guidelines to ED will not only decrease morbidity and mortality, but will also relieve the economic burden associated with treating this frequently encountered problem. Unfavorable outcomes, including physical harm to the patient and to those involved directly in their care have been well documented [2-5].

According to Lepouse et al., patients with delirium in the PACU setting were at an increased risk for injury, pain, hemorrhage, self-removal of catheters, and self-extubation, among other serious comorbid events [5]. Self-extubation and catheter removal can predispose patients to further adverse events including aspiration pneumonia or subsequent surgery for reexploration of surgical sites. Health care providers themselves risk injury during efforts to restrain and protect an agitated patient from harming themselves. In addition to the potential harm to patients and their care givers, ED has been shown to substantially increase resource utilization [5]. Agitated patients often face a more complicated and prolonged stay in the PACU, consisting of extensive medical regimens and additional ancillary staff [2-5]. While there is insufficient data quantifying the exact cost of ED management, the potential economic repercussions should not go ignored. At present, the need for improved ED screening and management protocols should be reiterated given the significant health and economic implications.

Two important factors that have contributed to the morbidity and mortality of ED include the ineffective screening and subsequent identification of at risk patients, as well as the lack of uniformity in diagnostic protocol. The studies which demonstrated variability of ED frequency with different surgical proceduresunderline the importance of preoperative screening and identifying patients at increased risk for ED $[5,33,41,48,49]$. Particularly, heightened surveillance in patients undergoing high risk operations, such as breast, abdominal, or facial surgery, will allow for appropriate prophylactic measurements and subsequently improve morbidity and mortality in ED cases of surgical etiology. Moreover, an overwhelming number of diagnostic tools are currently available, each of which are not without limitations. The advent of additional diagnostic conventions will only further complicate the ability to properly diagnose. The lack of consensus in establishing a standard diagnostic guideline will see a perpetuation of significant, yet preventable, adverse outcomes in the pediatric, adult, and geriatric populations.

\section{Limitations}

In 1961, Eckenhoff et al., first described what is now known as ED and called for a "suggested regimen of therapy". However, to date, management of ED remains purely anecdotal, relying entirely on clinical experience and judgement unique to each physician. The inability to establish a standard treatment regimen is likely due, in large part, to the complexity of the pharmacological agents currently available. For instance, there are a number of studies that exhibited an increased 
incidence of ED when treated with sevoflurane compared to halothane $[46,47]$. However, other studies have revealed that concomitant administration of oxycodone has led to halothane having a higher associated incidence of ED relative to sevoflurane [43]. The results of these studies have significant clinical ramifications as they suggest that medical management of ED is not as simple as choosing the anesthetic which prior studies have shown to be the safest. Rather, appropriate management of ED must take into consideration potential drug interactions that influence overall safety and efficacy. Regardless, establishing a standard therapy regimen will be vital in mitigating the morbidity and mortality of ED. As this literature review suggests, there has indeed been significant advances in understanding the etiology, risk factors, and medical management of this condition. With this being said, though, a standardized guideline or protocol for the prevention and managementof ED has not been created.

Lastly, prospective research efforts should focus on the generalizability of results between different age groups. Of particular importance is to ascertain whether results from pediatric studies are applicable to the adult and geriatric populations. The significance of this information becomes more pronounced when considering that the vast majority of ED research has been centered on the pediatric population. Given the multifaceted nature of ED, therapeutic inconsistencies across, and even within the different age groups, are expected. However, expanding the current understanding of treatment options across all ages will be vital to formulating a standard treatment protocol that will inevitably reduce morbidity, mortality, and resource utilization associated with ED.

\section{Competing interests}

The authors declare that they have no competing interests.

\section{Authors' contributions}

\begin{tabular}{|l|c|c|c|c|c|}
\hline Authors' contributions & OV & BK & YKJ & RS & GR \\
\hline Research concept and design & $\checkmark$ & $\checkmark$ & -- & $\checkmark$ & $\checkmark$ \\
\hline Collection and/or assembly of data & $\checkmark$ & $\checkmark$ & $\checkmark$ & -- & $\checkmark$ \\
\hline Data analysis and interpretation & $\checkmark$ & $\checkmark$ & $\checkmark$ & -- & $\checkmark$ \\
\hline Writing the article & $\checkmark$ & $\checkmark$ & - & -- & -- \\
\hline Critical revision of the article & $\checkmark$ & -- & -- & $\checkmark$ & $\checkmark$ \\
\hline Final approval of article & $\checkmark$ & -- & -- & -- & $\checkmark$ \\
\hline Statistical analysis & -- & -- & -- & -- & -- \\
\hline
\end{tabular}

Publication history

EIC: John Doyle, Case Western Reserve University, USA.

Received: 12-Jul-2015 Final Revised: 14-Aug-2015

Accepted: 24-Aug-2015 Published: 31-Aug-2015

\section{References}

1. Eckenhoff J, Kneale D and Dripps R. The incidence and etiology of postanestheticexcitment. A clinical survey. Anesthesiology. 1961; 22:667-73.

2. Olin K, Eriksdotter-Jonhagen M, Jansson A, Herrington MK, Kristiansson $\mathrm{M}$ and Permert J. Postoperative delirium in elderly patients after major abdominal surgery. Br J Surg. 2005; 92:1559-64. | Article I PubMed
3. Ely EW, Shintani A, Truman B, Speroff T, Gordon SM, Harrell FE, Jr., Inouye SK, Bernard GR and Dittus RS. Delirium as a predictor of mortality in mechanically ventilated patients in the intensive care unit. JAMA. 2004; 291:1753-62. | Article | PubMed

4. Leslie DL, Zhang Y, Holford TR, Bogardus ST, Leo-Summers LS and Inouye SK. Premature death associated with delirium at 1-year follow-up. Arch Intern Med. 2005; 165:1657-62. | Article | PubMed

5. Lepouse C, Lautner CA, Liu L, Gomis P and Leon A. Emergence delirium in adults in the post-anaesthesia care unit. Br J Anaesth. 2006; 96:747-53. | Article | PubMed

6. Sikich $\mathrm{N}$ and Lerman J. Development and psychometric evaluation of the pediatric anesthesia emergence delirium scale. Anesthesiology. 2004; 100:1138-45. | Article | PubMed

7. Sharma PT, Sieber FE, Zakriya KJ, Pauldine RW, Gerold KB, Hang J and Smith $\mathrm{TH}$. Recovery room delirium predicts postoperative delirium after hip-fracture repair. Anesth Analg. 2005; 101:1215-20. I Article I PubMed

8. O'Keeffe ST and Ni Chonchubhair A. Postoperative delirium in the elderly. Br J Anaesth. 1994; 73:673-87. I Article I PubMed

9. Fineberg SJ, Nandyala SV, Marquez-Lara A, Oglesby M, Patel AA and Singh $\mathrm{K}$. Incidence and risk factors for postoperative delirium after lumbar spine surgery. Spine (Phila Pa 1976). 2013; 38:1790-6. | Article I PubMed

10. Marcantonio ER, Goldman L, Orav EJ, Cook EF and Lee TH. The association of intraoperative factors with the development of postoperative delirium. Am J Med. 1998; 105:380-4. | Article | PubMed

11. Crosby $G$ and Culley DJ. Surgery and anesthesia: healing the body but harming the brain? Anesth Analg. 2011; 112:999-1001. | Article | PubMed Abstract | PubMed Full Text

12. John ER and Prichep LS. The anesthetic cascade: a theory of how anesthesia suppresses consciousness. Anesthesiology. 2005; 102:44771. | Article | PubMed

13. Weinberger NM. The medial geniculate, not the amygdala, as the root of auditory fear conditioning. Hear Res. 2011; 274:61-74. | Article | PubMed Abstract | PubMed Full Text

14. Rosenkranz JA, Venheim ER and Padival M. Chronic stress causes amygdala hyperexcitability in rodents. Biol Psychiatry. 2010; 67:1128-36. | Article | PubMed Abstract | PubMed Full Text

15. Guo YY, Liu SB, Cui GB, Ma L, Feng B, Xing JH, Yang Q, Li XQ, Wu YM, Xiong $L Z$, Zhang $W$ and Zhao MG. Acute stress induces down-regulation of large-conductance $\mathrm{Ca2+-activated} \mathrm{potassium} \mathrm{channels} \mathrm{in} \mathrm{the} \mathrm{lateral}$ amygdala. J Physiol. 2012; 590:875-86. | Article | PubMed Abstract | PubMed Full Text

16. McLott J, Jurecic J, Hemphill L and Dunn KS. Development of an amygdalocentric neurocircuitry-reactive aggression theoretical model of emergence delirium in posttraumatic stress disorder: an integrative literature review. AANA J. 2013; 81:379-84. | $\underline{\text { Article | PubMed }}$

17. Fong HK, Sands LP and Leung JM. The role of postoperative analgesia in delirium and cognitive decline in elderly patients: a systematic review. Anesth Analg. 2006; 102:1255-66. I Article I PubMed

18. Shigeta H, Yasui A, Nimura Y, Machida N, Kageyama M, Miura M, Menjo $\mathrm{M}$ and Ikeda K. Postoperative delirium and melatonin levels in elderly patients. Am J Surg. 2001; 182:449-54. | Article | PubMed

19. Hanania $\mathrm{M}$ and Kitain $\mathrm{E}$. Melatonin for treatment and prevention of postoperative delirium. Anesth Analg. 2002; 94:338-9. | Article | PubMed

20. Sultan SS. Assessment of role of perioperative melatonin in prevention and treatment of postoperative delirium after hip arthroplasty under spinal anesthesia in the elderly. Saudi J Anaesth. 2010; 4:169-73. | Article | PubMed Abstract | PubMed Full Text

21. Yasui Y, Masaki E and Kato F. Sevoflurane directly excites locus coeruleus neurons of rats. Anesthesiology. 2007; 107:992-1002. I Article I PubMed

22. Lim BG, Shen FY, Kim YB, Kim WB, Kim YS, Han HC, Lee MK, Kong MH and Kim YI. Possible role of GABAergic depolarization in neocortical neurons in generating hyperexcitatory behaviors during emergence from sevoflurane anesthesia in the rat. ASN Neuro. 2014; 6:e00141. | Article | PubMed Abstract | PubMed Full Text

23. Kazmierski J, Banys A, Latek J, Bourke J and Jaszewski R. Cortisol levels 
and neuropsychiatric diagnosis as markers of postoperative delirium: a prospective cohort study. Crit Care. 2013; 17:R38. | Article | PubMed Abstract | PubMed Full Text

24. McIntosh TK, Bush HL, Yeston NS, Grasberger R, Palter M, Aun F and Egdahl RH. Beta-endorphin, cortisol and postoperative delirium: a preliminary report. Psychoneuroendocrinology. 1985; 10:303-13. | Article | PubMed

25. Miyamoto E, Tomimoto H, Nakao Si S, Wakita H, Akiguchi I, Miyamoto $\mathrm{K}$ and Shingu K. Caudoputamen is damaged by hypocapnia during mechanical ventilation in a rat model of chronic cerebral hypoperfusion. Stroke. 2001; 32:2920-5. | Article | PubMed

26. Agnoletti V, Ansaloni L, Catena F, Chattat R, De Cataldis A, Di Nino G, Franceschi C, Gagliardi S, Melotti RM, Potalivo A and Taffurelli M. Postoperative Delirium after elective and emergency surgery: analysis and checking of risk factors. A study protocol. BMC Surg. 2005; 5:12. | Article | PubMed Abstract | PubMed Full Text

27. Yani S. Risk factors for postoperative delirium in the elderly. Alma Mater StudiorumUniversità di Bologna. 2011; 23.

28. Liu P, Li YW, Wang XS, Zou X, Zhang DZ, Wang DX and Li SZ. High serum interleukin- 6 level is associated with increased risk of delirium in elderly patients after noncardiac surgery: a prospective cohort study. Chin Med J (Engl). 2013; 126:3621-7. | PubMed

29. Abelha FJ, Fernandes V, Botelho M, Santos P, Santos A, Machado JC and Barros H. Apolipoprotein E e4 allele does not increase the risk of early postoperative delirium after major surgery. J Anesth. 2012. | Article | PubMed

30. Radtke FM, Franck M, Hagemann L, Seeling M, Wernecke KD and Spies $\mathrm{CD}$. Risk factors for inadequate emergence after anesthesia: emergence delirium and hypoactive emergence. Minerva Anestesiol. 2010; 76:394403. | Article | PubMed

31. Przybylo HJ, Martini DR, Mazurek AJ, Bracey E, Johnsen L and Cote CJ. Assessing behaviour in children emerging from anaesthesia: can we apply psychiatric diagnostic techniques? Paediatr Anaesth. 2003; 13:609-16. | Article | PubMed

32. Voepel-Lewis T, Malviya S and Tait AR. A prospective cohort study of emergence agitation in the pediatric postanesthesia care unit. Anesth Analg. 2003; 96:1625-30. | Article | PubMed

33. Bong $\mathrm{CL}$ and $\mathrm{Ng} \mathrm{AS}$. Evaluation of emergence delirium in Asian children using the Pediatric Anesthesia Emergence Delirium Scale. Paediatr Anaesth. 2009; 19:593-600. | Article | PubMed

34. Martini DR. Commentary: the diagnosis of delirium in pediatric patients J Am Acad Child Adolesc Psychiatry. 2005; 44:395-8. | Article | PubMed

35. Vlajkovic GP and Sindjelic RP. Emergence delirium in children: many questions, few answers. Anesth Analg. 2007; 104:84-91. | Article | PubMed

36. Doyle WL and Perrin L. Emergence delirium in a child given oral midazolam for conscious sedation. Ann Emerg Med. 1994; 24:1173-5. Article I PubMed

37. Zhang C, Li J, Zhao D and Wang Y. Prophylactic midazolam and clonidine for emergence from agitation in children after emergence from sevoflurane anesthesia: a meta-analysis. Clin Ther. 2013; 35:1622-31. | Article | PubMed

38. Cho EJ, Yoon SZ, Cho JE and Lee HW. Comparison of the effects of 0.03 and $0.05 \mathrm{mg} / \mathrm{kg}$ midazolam with placebo on prevention of emergence agitation in children having strabismus surgery. Anesthesiology. 2014; 120:1354-61. | Article | PubMed

39. Kwak KH. Emergence agitation/delirium: we still don't know. Korean J Anesthesiol. 2010; 59:73-4. | Article | PubMed Abstract | PubMed Full $\underline{\text { Text }}$

40. Welborn LG, Hannallah RS, Norden JM, Ruttimann UE and Callan CM. Comparison of emergence and recovery characteristics of sevoflurane, desflurane, and halothane in pediatric ambulatory patients. Anesth Analg. 1996; 83:917-20. | Article | PubMed

41. Davis PJ, Greenberg JA, Gendelman M and Fertal K. Recovery characteristics of sevoflurane and halothane in preschool-aged children undergoing bilateral myringotomy and pressure equalization tube insertion. Anesth Analg. 1999; 88:34-8. | Article | PubMed
42. Murray DJ, Cole JW, Shrock CD, Snider RJ and Martini JA. Sevoflurane versus halothane: effect of oxycodone premedication on emergence behaviour in children. Paediatr Anaesth. 2002; 12:308-12. | Article | PubMed

43. Grundmann U, Uth M, Eichner A, Wilhelm W and Larsen R. Total intravenous anaesthesia with propofol and remifentanil in paediatric patients: a comparison with a desflurane-nitrous oxide inhalation anaesthesia. Acta Anaesthesiol Scand. 1998; 42:845-50. | Article | PubMed

44. Wells LT and Rasch DK. Emergence "delirium" after sevoflurane anesthesia: a paranoid delusion? Anesth Analg. 1999; 88:1308-10. Article I PubMed

45. Aono J, Ueda W, Mamiya K, Takimoto E and Manabe M. Greater incidence of delirium during recovery from sevoflurane anesthesia in preschool boys. Anesthesiology. 1997; 87:1298-300. | Article | PubMed

46. Kuratani $\mathrm{N}$ and Oi Y. Greater incidence of emergence agitation in children after sevoflurane anesthesia as compared with halothane: a meta-analysis of randomized controlled trials. Anesthesiology. 2008; 109:225-32. | Article | PubMed Abstract | PubMed Full Text

47. Galford R. Problems in Anesthesiology: Approach to Diagnosis. Little, Brown. 1992; 451.

48. Yu D, Chai W, Sun $X$ and Yao L. Emergence agitation in adults: risk factors in 2,000 patients. Can J Anaesth. 2010; 57:843-8. | Article | PubMed

49. Riker RR, Picard JT and Fraser GL. Prospective evaluation of the Sedation-Agitation Scale for adult critically ill patients. Crit Care Med. 1999; 27:1325-9. | PubMed

50. Sessler CN, Gosnell MS, Grap MJ, Brophy GM, O'Neal PV, Keane KA, Tesoro EP and Elswick RK. The Richmond Agitation-Sedation Scale: validity and reliability in adult intensive care unit patients. Am J Respir Crit Care Med. 2002; 166:1338-44. | Article | PubMed

51. Weldon BC, Bell M and Craddock T. The effect of caudal analgesia on emergence agitation in children after sevoflurane versus halothane anesthesia. Anesth Analg. 2004; 98:321-6. | Article | PubMed

52. Aouad MT, Kanazi GE, Siddik-Sayyid SM, Gerges FJ, Rizk LB and Baraka AS. Preoperative caudal block prevents emergence agitation in children following sevoflurane anesthesia. Acta Anaesthesiol Scand. 2005; 49:300-4. | Article | PubMed

53. Tesoro S, Mezzetti D, Marchesini L and Peduto VA. Clonidine treatment for agitation in children after sevoflurane anesthesia. Anesth Analg. 2005; 101:1619-22. | Article | PubMed

54. Tazeroualti N, De Groote F, De Hert S, De Ville A, Dierick A and Van der Linden P. Oral clonidine vs midazolam in the prevention of sevofluraneinduced agitation in children. a prospective, randomized, controlled trial. Br J Anaesth. 2007; 98:667-71. | Article | PubMed

55. Bock M, Kunz P, Schreckenberger R, Graf BM, Martin E and Motsch J. Comparison of caudal and intravenous clonidine in the prevention of agitation after sevoflurane in children. Br J Anaesth. 2002; 88:790-6. I Article | PubMed

56. Guler G, Akin A, Tosun Z, Ors S, Esmaoglu A and Boyaci A. Single-dose dexmedetomidine reduces agitation and provides smooth extubation after pediatric adenotonsillectomy. Paediatr Anaesth. 2005; 15:762-6. | Article | PubMed

57. Ibacache ME, Munoz HR, Brandes V and Morales AL. Single-dose dexmedetomidine reduces agitation after sevoflurane anesthesia in children. Anesth Analg. 2004; 98:60-3. | Article | PubMed

58. Cole JW, Murray DJ, McAllister JD and Hirshberg GE. Emergence behaviour in children: defining the incidence of excitement and agitation following anaesthesia. Paediatr Anaesth. 2002; 12:442-7. | Article | PubMed

59. Dong YX, Meng LX, Wang Y, Zhang JJ, Zhao GY and Ma CH. The effect of remifentanil on the incidence of agitation on emergence from sevoflurane anaesthesia in children undergoing adenotonsillectomy. Anaesth Intensive Care. 2010; 38:718-22. | Article | PubMed

60. Galinkin JL, Fazi LM, Cuy RM, Chiavacci RM, Kurth CD, Shah UK, Jacobs IN and Watcha MF. Use of intranasal fentanyl in children undergoing myringotomy and tube placement during halothane and sevoflurane anesthesia. Anesthesiology. 2000; 93:1378-83. | Article | PubMed 
Viswanath et al. Journal of Anesthesiology \& Clinical Science 2015,

61. Cohen IT, Hannallah RS and Hummer KA. The incidence of emergence agitation associated with desflurane anesthesia in children is reduced by fentanyl. Anesth Analg. 2001; 93:88-91. | Article | PubMed

62. Cohen IT, Finkel JC, Hannallah RS, Hummer KA and Patel KM. The effect of fentanyl on the emergence characteristics after desflurane or sevoflurane anesthesia in children. Anesth Analg. 2002; 94:1178-81. | Article I PubMed

63. Finkel JC, Cohen IT, Hannallah RS, Patel KM, Kim MS, Hummer KA, Choi SS, Pena M, Schreiber SB and Zalzal G. The effect of intranasal fentanyl on the emergence characteristics after sevoflurane anesthesia in children undergoing surgery for bilateral myringotomy tube placement. Anesth Analg. 2001; 92:1164-8. I Article I PubMed

64. Pickard A, Davies $P$, Birnie $K$ and Beringer R. Systematic review and metaanalysis of the effect of intraoperative alpha(2)-adrenergic agonists on postoperative behaviour in children. Br J Anaesth. 2014; 112:982-90. | Article I PubMed

65. Dahmani S, Brasher C, Stany I, Golmard J, Skhiri A, Bruneau B, Nivoche $\mathrm{Y}$, Constant I and Murat I. Premedication with clonidine is superior to benzodiazepines. A meta analysis of published studies. Acta Anaesthesiol Scand. 2010; 54:397-402. | Article | PubMed

66. Enlow $W$ and Ardizzone L. A systematic review: dexmedetomidine versus placebo to decrease the incidence of emergence delirium/ emergence agitation (ED/EA) in pediatric patients. ClinSch Rev. 2008; 1:89-94. | Article

67. Isik B, Arslan M, Tunga AD and Kurtipek O. Dexmedetomidine decreases emergence agitation in pediatric patients after sevoflurane anesthesia without surgery. Paediatr Anaesth. 2006; 16:748-53. | Article I PubMed

68. Shukry M, Clyde MC, Kalarickal PL and Ramadhyani U. Does dexmedetomidine prevent emergence delirium in children after sevoflurane-based general anesthesia? Paediatr Anaesth. 2005; 15:1098-104. | Article | PubMed

69. Yang $\mathrm{S}$ and Lee $\mathrm{H}$. A dose-finding study of preoperative intravenous dexmedetomidine in children's emergence delirium after epiblepharon surgery. Eur J Ophthalmol. 2014; 24:417-23. | Article I PubMed

70. Ali MA and Abdellatif AA. Prevention of sevoflurane related emergence agitation in children undergoing adenotonsillectomy: A comparison of dexmedetomidine and propofol. Saudi J Anaesth. 2013; 7:296-300. I Article | PubMed Abstract | PubMed Full Text

71. Yuen VM, Hui TW, Irwin MG and Yuen MK. A comparison of intranasal dexmedetomidine and oral midazolam for premedication in pediatric anesthesia: a double-blinded randomized controlled trial. Anesth Analg. 2008; 106:1715-21. | Article | PubMed

72. Nagelhout J and Zaglaniczny K. Handbook of Nurse Anesthesia. Elsevier Saunders. 2005; 636.

73. Burns SM. Delirium during emergence from anesthesia: a case study. Crit Care Nurse. 2003; 23:66-9. I Article I PubMed

74. Casagrande AM. Propofol for office oral and maxillofacial anesthesia: the case against low-dose ketamine. J Oral Maxillofac Surg. 2006; 64:693-5. | Article I PubMed

75. Kararmaz A, Kaya S, Turhanoglu S and Ozyilmaz MA. Oral ketamine premedication can prevent emergence agitation in children after desflurane anaesthesia. Paediatr Anaesth. 2004; 14:477-82. | Article | PubMed

76. Abu-Shahwan I and Chowdary K. Ketamine is effective in decreasing the incidence of emergence agitation in children undergoing dental repair under sevoflurane general anesthesia. Paediatr Anaesth. 2007; 17:84650. | Article | PubMed

77. Treston G, Bell A, Cardwell R, Fincher G, Chand D and Cashion G. What is the nature of the emergence phenomenon when using intravenous or intramuscular ketamine for paediatric procedural sedation? Emerg Med Australas. 2009; 21:315-22. | Article | PubMed

78. Eghbal MH, Taregh S, Amin A and Sahmeddini MA. Ketamine improves postoperative pain and emergence agitation following adenotonsillectomy in children. A randomized clinical trial. Middle East J Anaesthesiol. 2013; 22:155-60. | Pdf | PubMed

79. Jia JE, Chen JY, Hu X and Li WX. A randomised study of intranasal dexmedetomidine and oral ketamine for premedication in children. Anaesthesia. 2013; 68:944-9. | Article | PubMed

80. Gleason OC. Delirium. Am Fam Physician. 2003; 67:1027-34. | Article | PubMed

\section{Citation:}

Viswanath O, Kerner B, Jean Y-K, Soto R and Rosen G.

Emergence delirium: a narrative review. J Anesthesiol Clin Sci. 2015; 4:2. http://dx.doi.org/10.7243/2049-9752-4-2 